\title{
The perception of the straight ahead with symmetrical retinal stimulation
}

\author{
LEONARD BROSGOLE \\ NAVAL TRAINING DEVICE CENTER
}

The location of a frame was varied horizontally with in a brightly illuminated Ganzfeld. Changing the position of the frame systematically shifted the apparent median plane, even though the entire retina was stimulated. It was concluded that the subjective straight ahead tends to be localized near the middle of a cognitive frame of reference, as opposed to the center of visual stimulation.

When a luminous background, presented in total darkness, is displaced off the side of the observer, the subjective straight ahead shifts toward the center of the visible field (Roelofs, 1935; Wapner, Werner, Bruell, \& Goldstein, 1953; Bruell \& Albee, 1955; Brosgole, 1966, 1967). This effect has also been demonstrated in cases where the entire surround has been shifted due to a visual defect (Bruell, 1958). It has been generally concluded, on the basis of such evidence, that the apparent median plane tends toward the center of retinal stimulation. In the above instances, the field used for shifting the center of retinal excitation has been the sole source of visual stimulation. It may, therefore, have served as a frame of reference. It is not clear, then, whether the apparent median plane is affected by the symmetry of the proximal stimulus or by some cognitive reference point.

The following study was designed to separate these factors. The location of a square frame was manipulated laterally within a brightly illuminated Ganzfeld. The square was thereby permitted to function as a frame of reference, because it was the only articulate visual stimulus available. Repositioning the frame, under such circumstances, did not affect the symmetry of visual space, since the entire retina was flooded with stimulation. The purpose of this experiment, therefore, was to determine whether varying the location of a frame would affect the apparent median plane with visual symmetry held constant.

Method

Apparatus. The apparatus consisted of a $270^{\circ}$ spherical projection screen, painted flat white and virtually free of texture. It was constructed of fiberglass, mounted on a frame of fiberboard and steel. The internal diameter of the screen was $20 \mathrm{ft}$.

The field was illuminated by four banks of 200-W incandescent bulbs to a brightness of $107.6 \mathrm{~mL}$. Photometric measurements across the surface of the screen indicated that the deviation in luminance did not exceed $1.1 \mathrm{~mL}$.
The $S$ was positioned on a chalse longue along a line bisecting the field. The floor of the Ganzfeld, as well as S's body, was covered with white fabric so as to complete the homogeneous surround. Stimuli were projected onto the screen by means of two slide projectors mounted directly above S's head. The stimuli were independently varied to the left and right with angular precision. They remained at a constant radial distance of $15 \mathrm{ft}$. from $S$.

Stimuli. The stimuli consisted of a circular target surrounded by a square frame. The target subtended a visual angle of $30^{\circ}$ and the frame $10^{\circ}$. They were projected upon the screen in positive contrast at a brightness of $140 \mathrm{~mL}$. The frame appeared in outline form. The width of its borders subtended $30^{\circ}$ of visual arc.

Procedure. The experiment consisted of three conditions. In each instance, $S$ saw the target surrounded by the frame. He was told to continuously fixate directly straight ahead and to ignore the frame at all times. He was required to advise $E$ as to how to manipulate the target laterally until it appeared to be straight ahead, i.e., perpendicular to the midline of his body. The position of the circular spot of light was recorded when $S$ indicated that it was in an apparent straight forward direction.

In the first condition, the frame was centered in the objective median plane. It was presented $4^{\circ}$ to the left in the second condition and $4^{\circ}$ to the right in the third. The frame appeared in each of its positions on eight different occasions, making a total of 24 trials. The trials were randomized differently for each S. The starting position of the target was counterbalanced over trials. It was presented either in the center of the frame or adjacent to one of its vertical borders.

Subjects. Seven males and one female participated in this study. Ranging in age from 18-24, their mean age was 19.6 years. They were undergraduates from C. W. Post College who were naive as to the purpose of the experiment.

\section{Resulis and Discussion}

The S's constant error from the objective median plane was calculated for each of the three conditions. The responses of every $S$ were biased to the right when the frame was set at true zero. A constant error of $2.5^{\circ}$ to the right was found in this instance. Shifting the frame to the left resulted in an error of $1.0^{\circ}$ to the right or $1.5^{\circ}$ to the left of the above settings. Displacing the square to the right yielded 
an average response of $3.7^{\circ}$ to right or $1.2^{\circ}$ to the right relative to the zero positioning of the frame. These differences were significant according to the Friedman two way analysis of variance $\left(X_{r} 2=14.25\right.$, $\mathrm{N}=8, \mathrm{~K}=3, \mathrm{p}<.001$ ). The Wilcoxon test indicated that while Condition 2 differed from 1 and 3 on the $1 \%$ confidence level ( $\mathrm{T}=0$ in each instance), the latter two treatments differed on the $5 \%$ level $(\mathrm{T}=4)$. It is clear, then, that the apparent median plane was systematically affected by the position of an articulate frame of reference within an empty visual field.

Our results also show that the effect of repositioning a field is not purely a scotopic phenomenon, which may be inferred from the prior studies in this area. In addition, the effect is also obtained when the location of a frame is varied radially, as well as in the fronto-parallel plane which is usually the case.

We may conclude that the subjective straight ahead does not tend to be localized midway between the lateral boundaries of visual stimulation. If this were the case, our Ss never would have been in error. However, it does appear to be influenced by the location of a cognitive frame of reference.

\section{References}

Brosgole, L. An analysis of induced motion. Port Washington: Naval Training Device Center, Tech. Rep. IH-48, February, 1966.

Brosgole, $\mathbf{L}$. The role of phenomenal displacement in the perception of the visual upright. Percept. \& Psychophys., 1967, in press. Bruell, J. H. Retinal local signs in homonymous hemianopsia, strabismus, and normal vision. Amer. J. Ophthal., 1958, 45, 662666 .

Bruell, J. H., \& Albee, G. W. Effect of asymmetrical retinal stimulation on the perception of the median plane. Percept. mot. Skills, 1955, 5, 133-139.

Roelofs, C. O. Optische Lokalisation. Arch. Augenheilk., 1935, $109,395-415$.

Wapner, S., Wemer, H., Bruell, J. H., \& Goldstein, A. G. Experiments on sensory-tonic field theory of perception: VII. Effect of asymmetrical extent and starting positions of figures on the visual apparent median plane. J. exp. Psychol., 1953, 46, 300307. 